
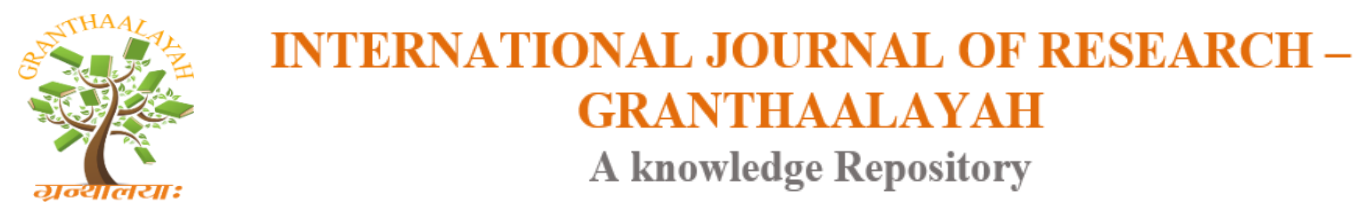

Science

\title{
INVESTIGATION OF LOW-TEMPERATURE FLUORESCENCE AND ABSORPTION SPECTRA OF HIGHLY STABLE MERO-CYANINES DERIVATIVES OF 2, 6-DI-TERT-BUTYL-4-[R]-CYCLOHEXA-2, 5- DIENONE
}

\author{
Nataliya Obernikhina ${ }^{* 1}$, Alexey Kachkovsky ${ }^{2}$, Viktor Kurdyukov ${ }^{3}$, Yuriy Piryatinski ${ }^{4}$ \\ ${ }^{1}$ Bogomolets National Medical University, Department of Bioorganic and Biological Chemistry, \\ 34 Peremogy Ave., 03055, Kyiv, Ukraine \\ ${ }^{2}$ Institute of Bioorganic Chemistry and Petrochemistry NAS of Ukraine, 1 Murmanska str., \\ Kyiv, 02660, Ukraine \\ ${ }^{3}$ Institute of Organic Chemistry NAS of Ukraine, 5 Murmanska str.; Kyiv, 02660, Ukraine \\ ${ }^{4}$ Institute of Physics NAS of Ukraine, 46 Nauki Ave., Kyiv, 03039, Ukraine
}

\begin{abstract}
This work presents the results of the investigation of the dependence of the fluorescence and absorption spectra of merocyanines, derivatives of the 2,6-di-tret-butyl-4-[R]-cyclohexa-2,5dienone, on the nature of donor end groups (pyridinium, quinolinium, pyrilium, benzo[c,d]indolium, benzoimidindolium). Quantum-chemical calculation of the distribution was organized to electronic density and lengths of the relationships, which has shown that introduction tert-butyl groups in nucleus cyclohexa-2,5-dienone practically does not influence upon the general characteristic merocyanines in contrast with hydrogen. The stability merocyanines vastly increases when entering tert-butyl groups in cyclohexa-2,5-dienone. But such three-dementional groups vastly complicate the bands of the absorption, which become broader, have a complex oscillatory structure. So more suitable spectrums turned out to be for interpreting electronic transition to fluorescences, to measure at the temperature of the fluid nitrogen. As it is seen, spectral bands become more structuring with clearly marked by maximum of the transition. Well-defined $0 \rightarrow 0$ vibronical transition was found at use of the lowtemperature fluorescent spectra. Merocyanines with highly stable tert-butyl groups can be used as fluorescence probes and labels in chemistry and biology, active and passive components for tunable dye lasers, highly effective materials for non-linear optic.
\end{abstract}

Highlights

- Dependence of the low-temperature fluorescence and absorption spectra of theses merocyanines on the nature of donor end groups a presented.

- Well-defined $0 `>0$ vibronical transition of merocyanines, derivatives of the 2,6-di-tretbutyl-4-[R]-cyclohexa-2,5-dienone at use of the low-temperature fluorescent spectra was found.

- Merocyanines with highly stable tert-butyl groups can be used as fluorescence probes and labels in chemistry and biology. 
Keywords: Cyanine Dyes; Electron Structure; Absorption Spectra; Low-Temperature Fluorescence Spectra; Quantum-Chemical Calculations.

Cite This Article: Nataliya Obernikhina, Alexey Kachkovsky, Viktor Kurdyukov, and Yuriy Piryatinski. (2017). "INVESTIGATION OF LOW-TEMPERATURE FLUORESCENCE AND ABSORPTION SPECTRA OF HIGHLY STABLE MERO-CYANINES DERIVATIVES OF 2, 6-DI-TERT-BUTYL-4-[R]-CYCLOHEXA-2, 5-DIENONE." International Journal of Research - Granthaalayah, 5(12), 435-451. https://doi.org/10.29121/granthaalayah.v5.i12.2017.530.

\section{Introduction}

The neutral merocyanines as donor-acceptor $\pi$-electron conjugated molecules are well-known highly sensitive sensors on solvent polarity [1,2]; and hence they are used upon quantumchemical modelling of the solvatochromism [2,3]. Recent growing interest in the merocyanines is connected with use of the similar compounds as highly effective materials for non-linear optics [4]. It was established that the higher hyper-polarizabilities $\beta_{\mathrm{o}}$ and $\gamma_{\mathrm{o}}$, are unambiguously determined by the donor and acceptor strengths of the terminal residues and, correspondingly, by the alternation of the lengths of the carbon-carbon bonds in the conjugated chain (so called parameter BLA) [4,5]. Also, it was shown in the framework of the topological (Huekel) approximation [5] that the BLA value can be both negative and positive, depending on the donor and acceptor strengths of the end groups; providing the BLA $=0$, so called "cyanine limit" can be reached $[4,5]$.

This highly polarizability is caused by the features of the electron structure of the linear donoracceptor conjugated molecules. One assumes in the simplest theoretical model, that merocyanines can be described in terms of the resonance between a neutral form $\mathbf{A}$ and a chargeseparated form $\mathbf{B}$ as highly polarizable donor-acceptor $\pi$-systems:

$$
\underset{\mathbf{A}}{\mathrm{D}-(\mathrm{CH}=\mathrm{CH})_{n}-\mathrm{A}} \stackrel{\leftrightarrow}{\leftrightarrow \mathrm{D}^{+}=} \underset{\mathbf{B}}{(\mathrm{CH}-\mathrm{CH})_{n}=\mathrm{A}^{-}}
$$

It was postulated that providing the equal weights of both forms, there arises the cyanine-like structure which is characterized by the minimum bond length alternation and experimentally by the maximum in the wavelength of the first absorption band [3]. However, the calculation in the non-empirical $a b$ initio approximation (with STO 6-31(d,p) basis set) has shown to give the considerable alternation of the CC-bond lengths in the chain for the pyridocyanines, so that the lengths of the double bonds are equal nearly $1.36 \AA$, while the single bond length exceeds 1.43 $\AA$. The similar large difference in the lengths of the neighboring CC-bonds was found to exist in other merocyanine derivatives of the oxystyryls containing quinoline, indolenine and benzo[c,d]indolenine residues as a donor end group [6]. Based on study of the absorption spectra and results of the quantum-chemical calculation, we proposed in our previous paper [6] that the relative longwavelength absorption of such neutral $\pi$-systems as merocyanines appears to be caused by the considerable redistribution of the electron density upon excitation, similarly to typical cyanine dyes. Then one should expect that the influence of the molecular topology on the spectral properties will be similar to the symmetrical cyanines. 


\section{Objects and Methodology}

We have chosen the derivatives of the 2, 6-di-tret-butyl substituted cyclohexa-2,5-dienone, containing variable donor terminal residues with different basities which are traditionally used as end groups in the typical cyanines [7-9]. They can be presented by a general formula 1. Also, some unsubstituted merocyanines 2 were studied.

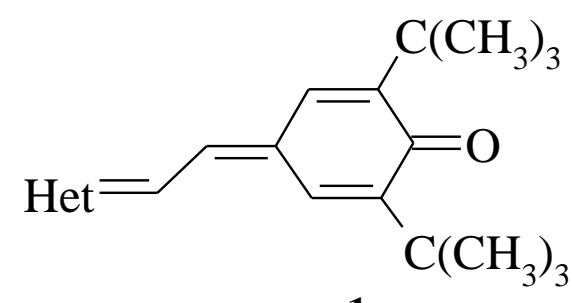

1

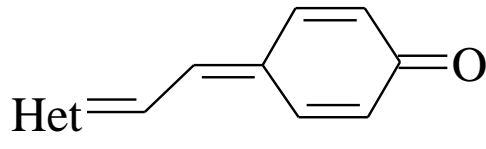

2

The spectral properties of the neutral dyes 1 and 2 have been compared with the corresponding data of the cationic oxystyryls 3 and symmetrical cyanines 4 .<smiles>[CH]/C=C/c1ccc(O)cc1</smiles>

3<smiles>[CH]C=CC=C[CH]</smiles>

4

Here Het =:<smiles>C=C1C=CN(C)C=C1</smiles>

Py<smiles>C=C1C=CN(C)c2ccccc21</smiles>

Qu<smiles>C=C1C=C(C(C)(C)C)OC(C(C)(C)C)=C1</smiles>

PI<smiles>C=C1N(CC)c2ccccc2N1CCCC</smiles>

BIm<smiles>C=C1N(C)c2ccccc2C1(C)C</smiles>

In

Het+:<smiles>Cc1cc[n+](C)cc1</smiles>

Py<smiles>Cc1cc[n+](C)c2ccccc12</smiles>

Qu<smiles>CC1=[N+](C)c2cccc3cccc1c23</smiles>

PI<smiles>CCCCCCCn1c(C)[n+](CC)c2ccccc21</smiles>

BIm<smiles>CC1=[N+](C)c2ccccc2C1(C)C</smiles>

In

It is well-known that going from the dyes containing the pyridine residue (Py) to their quinoanalogues $(\mathbf{Q u})$ simulates decreasing of the donor strength (or basicity) by the linear 
annelation, whereas influence of the change of the electronegativity of heteroatom providing the same bond topology can be studied by comparing the pair dyes, contained $\mathbf{P y}$ and $\mathbf{P l}$ residues derivatives. Other pair, 1-In and 1-BIm, demonstrates the considerable increase of the basicity upon minimal change in the chemical constitution, although the $\pi$-shell increasing in 2 electrons (LEP of the nitrogen atom which is included in the total conjugated system of the merocyanine). On the other hand, heterocyclic residues as end groups differ each other by their effective lengths [11]. Introducing of the bulk $\mathrm{t}-\mathrm{Bu}$ substituents in the cyclohexa-2,5-dienone residue of the acceptor residue leads to the appreciable increase of the chemical and photochemical stability [12].

Absorption spectra were recorded on a spectrophotometer Shimadzu UV3100. Spectral grade acetonitrile as polar solvent and toluene as non-polar solvent were mainly used for spectral measurements.

Fluorescence Spectra: The stationary and time-resolved fluorescence spectra were recorded with an SPM-2 monochromator with photoelectric attachment. The spectral slit width was 0.2-0.4 $\mathrm{nm}$. The fluorescence was excited by 337.1-nm pulsed nitrogen laser with a pulse repetition rate of $100 \mathrm{~Hz}$, pulse duration of $10 \mathrm{~ns}$, and pulse power of $5 \mathrm{~kW}$.

Quantum-Chemical Calculations: The equilibrium geometry of the dye molecules was obtained in the non-empirical ab initio approximation (with STO 6-31(d,p) basis set) and [16]; in the excited state, the configuration interaction includes all single and many electron promotions from 3 highest occupied orbitals to 3 lowest vacant MOs (MOPAC package). We supposed that the molecules in the so called "fluorescent" excited relaxed state remain planar; the shortlifetime twisting component is not fluorescent.

Numeration of atoms, bond length and bond orders are presented in the scheme:

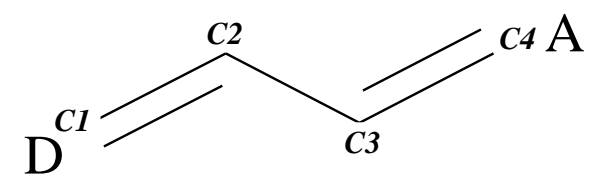

\section{Results and Discussion}

\subsection{Synthesis}

Synthesis of the dye 2, 6-Di-tert-butyl-4-[2-(1-methyl-1H-pyridin-4-ylidene)-ethylidene]cyclohexa-2, 5-dienone 1-Py was described earlier [12]. The compounds of the general formula 1 were synthesized by scheme. 


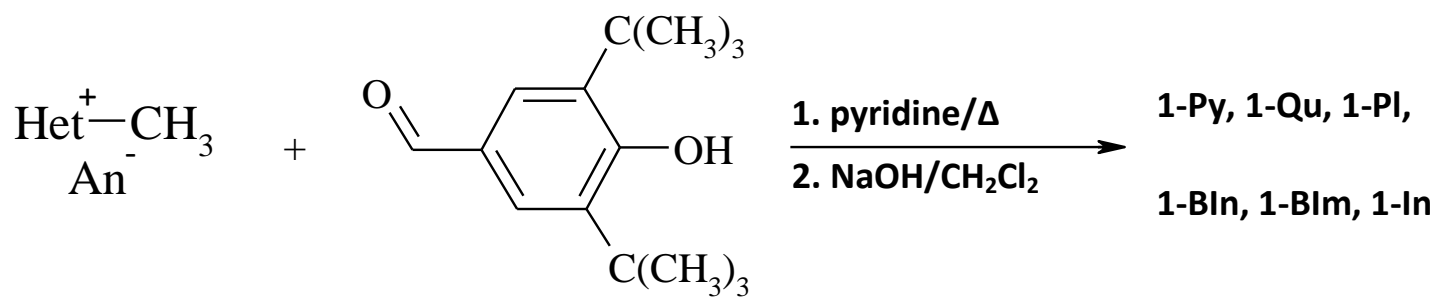

2,6-Di-tert-butyl-4-[2-(1-methyl-1H-quinolin-4-ylidene)-ethylidene]-cyclohexa-2,5-dienone

(1-Qu). Solution from $0.99 \mathrm{~g}$ (3 mmole) 1,4-dimethylquinolinium p-toluensulfonate and $0.77 \mathrm{~g}$ (3,3 mmole) 3,5-di-tret-buthyl-4-hydroxibenzaldehyde in $15 \mathrm{ml}$ from dry pyridine and $0.30 \mathrm{~g}$ (3,5 mmole) piperydine was boiled during $2 \mathrm{~h}$ and then cooled to the room temperature. Solvent was removed at the diminished pressure. The residue was dissolved in dichloromethane and shacked in a separating funnel with $10 \%$ aqueous solution of sodium hydroxyde. The organic layer was washed by water, dried by waterless potash. Resulting product was chromatographed on aluminium oxide and recrystallized from acetonitrile for cleaning, yield $0.73 \mathrm{~g}(65 \%)$, m. p.(decomp) $241-243{ }^{\circ} \mathrm{C}$. ${ }^{1} \mathrm{H}-\mathrm{NMR}$ (DMSO d6), $\delta$ (ppm): 1.27 (s, 18H, t-Bu), 3.70 (s, 3H, NMe), 6.92 (d, J= 13.5 Hz, 1H, H-chain), 7.06 (d, J= 7.2 Hz, 1H, ArH), 7.38 (t, J= 7.2 Hz, 2H,ArH), 7.49-7.71 (m, 5H, Ar-H and H-chain), 8.32 (d, J=7.2 Hz, 1H, Ar-H). Elemental analysis: calcd for $\mathrm{C}_{26} \mathrm{H}_{31} \mathrm{NO}$ : C, 83.60; H, 8.37; N, 3.75; O, 4.28. Found: C, 83.45; H, 8.28; N, 4.00.

2,6-Di-tert-butyl-4-[2-(2,6-di-tert-butyl-pyran-4-ylidene)-ethylidene]-cyclohexa-2,5-dienone (1-Pl) was prepared in the same way of $0.92 \mathrm{~g}$ (3 mmole) 2,6-di-tret-butyl-4-methylpyrilium perchlorate. In this case $2 \%$ sodium hydroxyde solution was used instead $10 \%$. The product was crystallized from the mixture of dichloromethane and n-hexane, yield $0.83 \mathrm{~g}(66 \%)$, m.p.(decomp) $234-235^{\circ} \mathrm{C} .{ }^{1} \mathrm{H}-\mathrm{NMR}\left(\mathrm{CDCl}_{3}\right), \delta(\mathrm{ppm}): 1.18$ (s, 9H, t-Bu), 1.22 (s, 9H, t-Bu), $1.28(\mathrm{~s}, 9 \mathrm{H}, \mathrm{t}-\mathrm{Bu}), 1.30$ (s, 9H, t-Bu), 5.91 (s, 1H, Ar-H), 6.06 (d, J= 13.5 Hz, 1H, H-chain), 6.29 (s, 1H, Ar-H), 6.91 (s, 1H, Ar-H), 7.04 (d, J=13.5 Hz, h-chain), 7.42 (s, 1H, Ar-H). Elemental analysis: calcd for $\mathrm{C}_{29} \mathrm{H}_{42} \mathrm{O}_{2}: \mathrm{C}, 82.41 ; \mathrm{H}, 10.02$; O, 7.57. Found: C, 82.43; H, 10.00 .

\section{2,6-Di-tert-butyl-4-[2-(1-methyl-1H-benzo[c,d]indol-2-ylidene)-ethylidene]-cyclohexa-2,5- dienone}

(1-BIn) was prepared in the same way from $0.81 \mathrm{~g}$ (3 mmole) 1,2-dimethylbenzo[c,d[indolium tetrachloroborate, yield $0.52 \mathrm{~g}$ (44\%), m.p.(decomp) $244-245^{\circ} \mathrm{C} .{ }^{1} \mathrm{H}-\mathrm{NMR}$ (DMSO d6), $\delta$ (ppm):1.28 (s, 9H, t-Bu), $1.32(\mathrm{~s}, 9 \mathrm{H}, \mathrm{t}-\mathrm{Bu}), 3.58(\mathrm{~s}, 3 \mathrm{H}, \mathrm{NMe}), 6.66(\mathrm{~d}, \mathrm{~J}=13.5 \mathrm{~Hz}, 1 \mathrm{H}, \mathrm{H}-$ chain), 6.99 (d, J=6.3 Hz, 1H, ArH), 7.30-7.47 (m, 3H, Ar-H), 7.64-7.77 (m, 2H, Ar-H), 7.85$7.98(\mathrm{~m}, 2 \mathrm{H}, \mathrm{Ar}-\mathrm{H}$ and H-chain), $8.42(\mathrm{~d}, \mathrm{~J}=6.3 \mathrm{~Hz}, 1 \mathrm{H}, \mathrm{Ar}-\mathrm{H})$. Elemental analysis: calcd for $\mathrm{C}_{28} \mathrm{H}_{31} \mathrm{NO}: \mathrm{C}, 84.59 ; \mathrm{H}, 7.86$; N, 3.52; O, 4.02. Found: C, 84.41; H, 7.75; N, 3.49.

2,6-Di-tert-butyl-4-[2-(1,3-diethyl-1,3-dihydro-benzoimidazol-2-ylidene)-ethylidene]-cyclohexa2,5-dienone

(1-BIm) was prepared in the same way from $0.95 \mathrm{~g}$ (3 mmole) 1,3-diethyl-2-methyl-3Hbenzoimidazolium iodide, yield $0.95 \mathrm{~g}$ (52\%), m.p.(decomp) $197-199{ }^{\circ} \mathrm{C} .{ }^{1} \mathrm{H}-\mathrm{NMR}$ (DMSO d6), $\delta(\mathrm{ppm}): 1.32$ (s, 18H, t-Bu), $1.42(\mathrm{t}, \mathrm{J}=7.2 \mathrm{~Hz}, 6 \mathrm{H}, \mathrm{Me}), 4.41$ (q, J=7.2 Hz, 4H, NCH$)_{2}, 7.00$ (d, $\mathrm{J}=15.0 \mathrm{~Hz}, 1 \mathrm{H}, \mathrm{H}-\mathrm{chain}), 7.20$ (ws, 2H, Ar-H), 7.34-7.39 (m, 2H, Ar-H), 7.41 (d, J=15.0 Hz, 
$1 \mathrm{H}, \mathrm{H}$-chain), 7.69 (m, 2H, Ar-H). Elemental analysis: calcd for $\mathrm{C}_{27} \mathrm{H}_{36} \mathrm{~N}_{2} \mathrm{O}: \mathrm{C}, 80.15 ; \mathrm{H}, 8.97$; N, 6.92; O, 3.95. Found: C, 80.20; H, 8.90; N, 6.92.

2,6-Di-tert-butyl-4-[2-(,-3,3trdimethyl-1,3-dihydro-indol-2-ylidene)-ethylidene]-cyclohexa-2,5dienone

(1-In) was prepared in the same way from $0.90 \mathrm{~g}(3 \mathrm{mmole})$ 1,2,3,3-tetramethyl-3H-indolium iodide, yield $0.68 \mathrm{~g}(58 \%)$, m.p.(decomp) $137-139^{\circ} \mathrm{C} .{ }^{1} \mathrm{H}-\mathrm{NMR}$ (DMSO d6), $\delta$ (ppm): 1.29 (ws, $18 \mathrm{H}, \mathrm{t}-\mathrm{Bu}), 1.63$ (s, 6H, Me), 3.43 (s, 3H, NMe), 6.17 (d, J=13.5 Hz, 1H, H-chain), 7.02 (t, J= $7.2 \mathrm{~Hz}, 1 \mathrm{H}, \mathrm{Ar}-\mathrm{H}), 7.10$ (d, J= 7.5 Hz, 1H, Ar-H), 7.22 (ws, 1H, Ar-H), 7.27 (t, J=7.2 Hz, 1H, Ar-H), 7.42 (d, J= 7.5 Hz, 1H, Ar-H), 7.56 (ws, 1H, Ar-H), 7.64 (d, J= 13.5Hz, 1H, H-chain).. Elemental analysis: calcd for $\mathrm{C}_{27} \mathrm{H}_{35} \mathrm{NO}: \mathrm{C}, 83.24 ; \mathrm{H}, 9.06 ; \mathrm{N}, 3.60 ; \mathrm{O}, 4.11$. Found: $\mathrm{C}, 83.18 ; \mathrm{H}$, 9.07; N, 3.50.

\subsection{Change of Electron Distribution and Molecular Geometry Upon Excitation}

The calculation seen from Figure 1 shows that going from the model unsubstituted 2-Py to its t$\mathrm{Bu}$-derivative did not influence practically the atomic charges and carbon-carbon bond lengths in the chain.
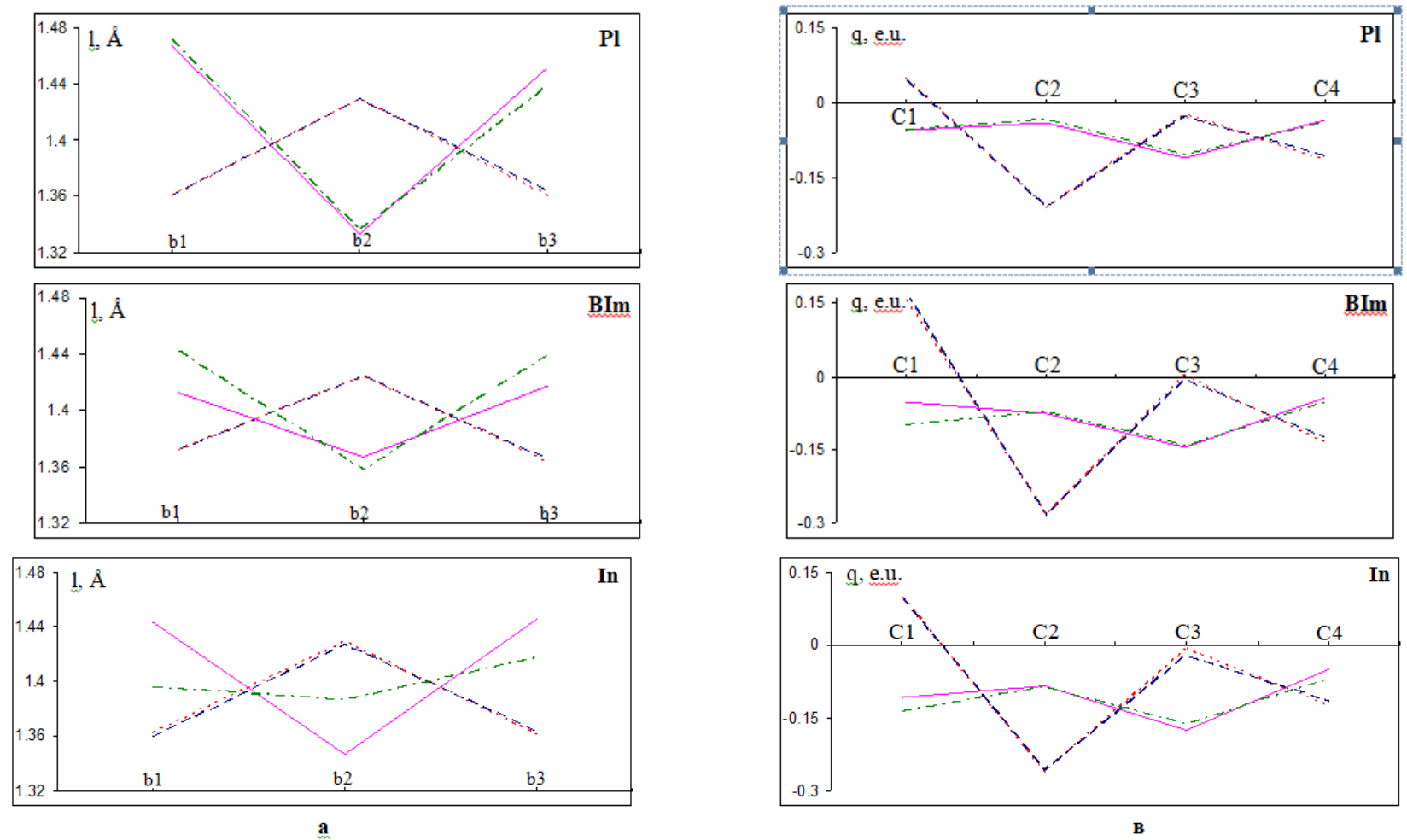

Figure 1: Bond lengths (a) and charge (b) in the merocyanines 1-Pl, 1-BIm, 1-In, 2-Pl, 2-BIm, 2 In ground state 1-Pl, 1-BIm, 1-In, excited state 1-Pl, 1-BIm, 1-In, ground state 2-Pl, 2-BIm, 2-In, excited state 2-Pl, 2-BIm, 2-In. 
The practically coincidence of the molecular geometry and charge distribution is obtained in the other dyes with the cyclic donor terminal group $\mathrm{Het}=(\mathrm{Qu}, \mathrm{Pl})$ and their substituted derivatives, unlike them, the indo-, benzo[c,d]indo- and imidomerocyanines (1-In, 1-BIn and 1-BIm) have demonstrated the appreciable changes of the charges in the excited state and relaxed bond lengths, so that the alternation of the charges and bond lengths somewhat decrease (see Figure 1). That is why, we have taken into consideration t-Bu substituents in the explicit form in our calculation, instead of the traditional modellig of them by hydrogen atoms or even methyl groups.

The main calculated data (the charges and bond lengths in the open chain) are presented in



A
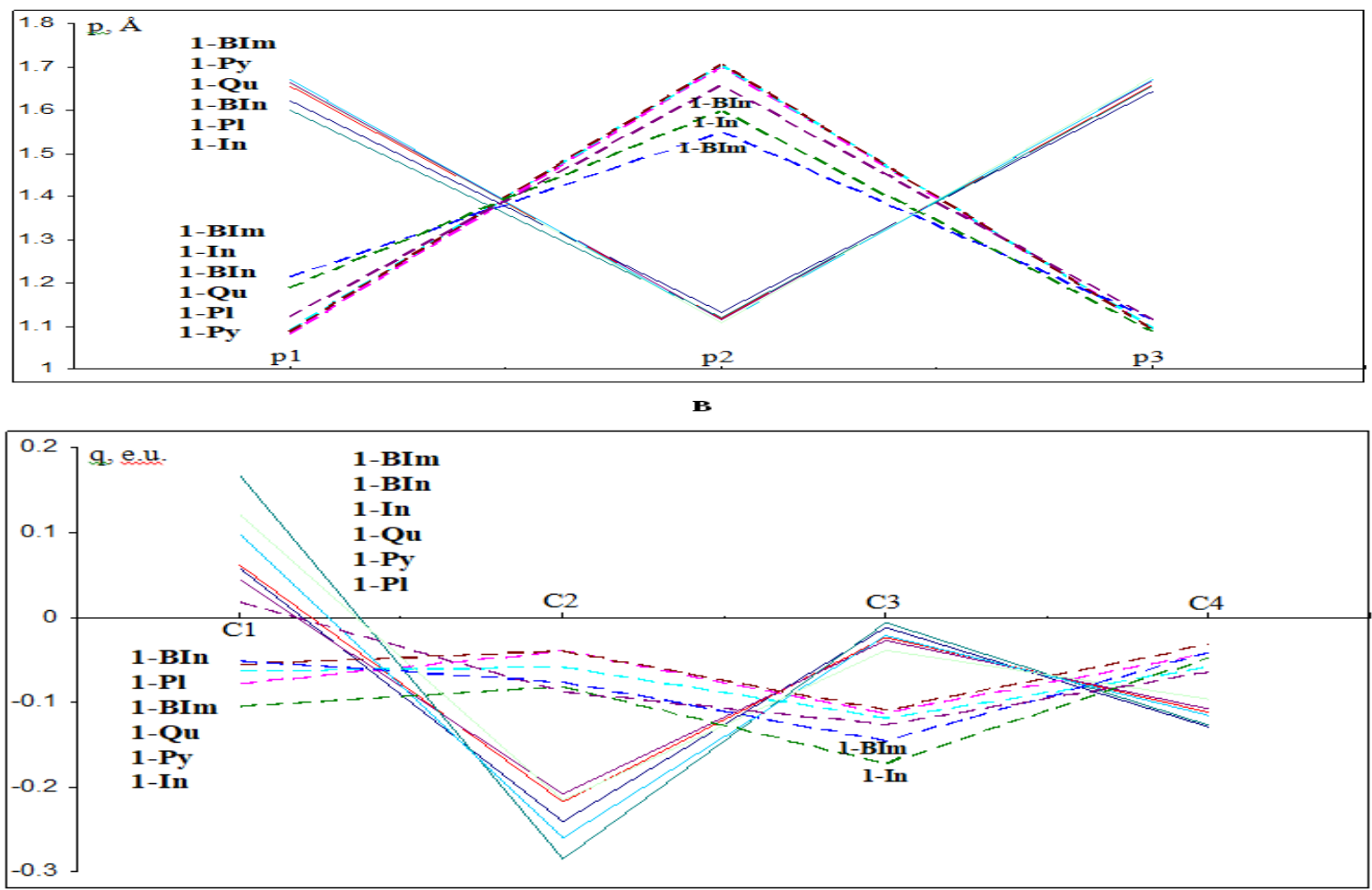

c

Figure 2: Bond length (a), charge (b) and bond orders (c) in the merocyanines 1.ground state and excited state 
One can easily see from Figure 2a that there are considerable alternations of the bond lengths. So, the length of the bond neighboring with the donor group Het= is comparatively short and depends weakly on the basicity of the terminal heterocycle Het=: 1.360-1.372 $\AA$, while the length of the next bond is essentially longer: 1.424-1.430 $\AA$; the length of the CC-bond neighboring with the acceptor group is practically insensitive to the nature of the donor residue: $\approx 1.365 \AA$. In the contrast, the lengths in the relaxed excited state are seen from Figure $2 \mathbf{a}$ and are appreciably determined by the donor strength (basicity) of the end group Het=, particularly, the bond $\mathrm{C} 1-\mathrm{C} 2$; the longest bond length is in the pyridomerocyanine 1-Py $(1.479 \AA)$, and minimum $\mathrm{C} 1-\mathrm{C} 2=1.413 \AA$ is in the imidomerocyanine 1-BIm. The next 2 bonds in the chain are less sensitive to the topology of the donor residue in the excited state, although nevertheless the alternation of the bond lengths in the indo- and imidomerocyanines is considerably smaller than in other dyes: 1-Py, 1-Qu, 1-PI. It should be mentioned that excitation causes the inversion in the ordering of the bonds with the shorter and longer length, similarly to the polyenes [13]. The changes of the bond lengths upon relaxation in the excited state are collected in the Table $\mathbf{1 .}$

Table 1: Change of the bond length $(\Delta \mathrm{l})$, bond orders $(\Delta \mathrm{p})$ and atomic charges $(\Delta \mathrm{q})$ upon excitation

\begin{tabular}{|c|c|c|c|c|c|c|}
\hline & & $\Delta 1, \AA$ & $\Delta \mathrm{p}, \AA$ & $\delta$ & $\Delta q$, e.u. & \\
\hline \multirow[t]{4}{*}{$1-\mathrm{Py}$} & $\mathrm{C} 1-\mathrm{C} 2$ & 0.113 & -0.541 & 1.073 & -0.135 & $\mathrm{C} 1$ \\
\hline & $\mathrm{C} 2-\mathrm{C} 3$ & -0.095 & 0.568 & & 0.202 & $\mathrm{C} 2$ \\
\hline & $\mathrm{C} 3-\mathrm{C} 4$ & 0.090 & -0.549 & & -0.103 & C3 \\
\hline & & & & & 0.085 & $\mathrm{C} 4$ \\
\hline \multirow[t]{4}{*}{$1-\mathrm{Qu}$} & $\mathrm{C} 1-\mathrm{C} 2$ & 0.102 & -0.567 & 1.124 & -0.125 & $\mathrm{C} 1$ \\
\hline & $\mathrm{C} 2-\mathrm{C} 3$ & -0.094 & 0.583 & & 0.158 & $\mathrm{C} 2$ \\
\hline & $\mathrm{C} 3-\mathrm{C} 4$ & 0.090 & -0.566 & & -0.096 & C3 \\
\hline & & & & & 0.053 & $\mathrm{C} 4$ \\
\hline \multirow[t]{4}{*}{$1-\mathrm{Pl}$} & $\mathrm{C} 1-\mathrm{C} 2$ & 0.107 & -0.580 & 1.136 & -0.100 & $\overline{\mathrm{C} 1}$ \\
\hline & $\mathrm{C} 2-\mathrm{C} 3$ & -0.096 & 0.591 & & 0.168 & $\mathrm{C} 2$ \\
\hline & $\mathrm{C} 3-\mathrm{C} 4$ & 0.089 & -0.577 & & -0.083 & C3 \\
\hline & & & & & 0.075 & $\mathrm{C} 4$ \\
\hline \multirow[t]{3}{*}{ 1-BIn } & $\mathrm{C} 1-\mathrm{C} 2$ & 0.076 & -0.542 & 1.115 & -0.104 & $\mathrm{C} 1$ \\
\hline & $\mathrm{C} 2-\mathrm{C} 3$ & -0.070 & 0.549 & & 0.038 & $\mathrm{C} 2$ \\
\hline & $\mathrm{C} 3-\mathrm{C} 4$ & 0.072 & -0.561 & & -0.088 & C3 \\
\hline
\end{tabular}




\begin{tabular}{|c|c|c|c|c|c|c|}
\hline & & & & & 0.031 & $\mathrm{C} 4$ \\
\hline \multirow{3}{*}{ 1-BIm } & $\mathrm{C} 1-\mathrm{C} 2$ & 0.041 & -0.388 & 0.892 & -0.220 & $\mathrm{C} 1$ \\
\cline { 2 - 7 } & $\mathrm{C} 2-\mathrm{C} 3$ & -0.056 & 0.427 & & 0.208 & $\mathrm{C} 2$ \\
\cline { 2 - 7 } & $\mathrm{C} 3-\mathrm{C} 4$ & 0.053 & -0.540 & & -0.140 & $\mathrm{C} 3$ \\
\cline { 2 - 7 } & & & & & 0.085 & $\mathrm{C} 4$ \\
\hline \multirow{7}{*}{ 1-In } & $\mathrm{C} 1-\mathrm{C} 2$ & 0.085 & -0.481 & 1.013 & -0.204 & $\mathrm{C} 1$ \\
\cline { 2 - 7 } & $\mathrm{C} 2-\mathrm{C} 3$ & -0.08 & 0.490 & & 0.178 & $\mathrm{C} 2$ \\
\cline { 2 - 7 } & $\mathrm{C} 3-\mathrm{C} 4$ & 0.082 & -0.585 & & -0.153 & $\mathrm{C} 3$ \\
\cline { 2 - 7 } & & & & & 0.066 & $\mathrm{C} 4$ \\
\hline
\end{tabular}

Remark: parameter $\delta$ is calculated by the equ. (2).

It is seen that maximum changes of the equilibrium molecular geometry occur in the pyridoquino- and piranomerocyanines (1-Py, 1-Qu, 1-Pl), whereas indo-, benzo[c,d]indo- and imidomerocyanines show the significantly smaller geometrical changes, because of the equalization of the bond lengths in the excited state. Also, it is interesting to compare the changes of the bond lengths upon relaxation in the excited state, $1_{\mu v}$, with the changes of the bond orders, $\mathrm{p}_{\mu \nu}$, so as there exists the relation between these two values [13]:

$$
1_{\mu v}(\AA)=\mathrm{a}-\mathrm{bp}_{\mu v},
$$

where $\mathrm{a}$ and $\mathrm{b}$ are the parameters (in the PPP approximation, $\mathrm{a}=1.54 \AA, \mathrm{b}=0.14 \AA$ ). Our calculations have shown that the changes of the bond orders, $\mathrm{p}_{\mu v}$, upon excitation (upon the same equilibrium molecular geometry, in accordance with the Frank-Condon rule [13]) coincide practically for the merocyanines containing pyrido-, quino- and pirano- residues (1-Py, 1-Qu, 1Pl), while similar magnitudes for the indo-, benzo[c,d]indo- and imidomerocyanines somewhat decrease, as it is seen from Table 1 . Thus, comparing the changes of the bond orders $\left(\Delta \mathrm{p}_{\mu \nu}\right)$ and lengths of the relaxed bonds $\left(\Delta \mathrm{l}_{\mu v}\right)$ as well as taking into consideration the equation (1), we should propose that the considerable dependence of the bond $\mathrm{C} 1-\mathrm{C} 2$ on the basicity of the donor group Het= is reached only after relaxation of the molecular geometry in the excited state.

The performed calculation have shown also the appreciable changes in electron distribution upon excitation (Table 1), although the atomic charges in the chain less depend on the nature of the donor residue, in compare with the lengths or order of the bonds.

The changes of the electron density distribution upon varying of the donor strength of end group Het $=$ lead, of course, to changes of the dipole moments in both ground and excited states, as it was shown earlier for the unsubstitued merocyanines 2 [6]. Introducing of the $\mathrm{t}$-Bu donor substituents causes the acceptor strength of the cyclohexa-2, 5-dienone residue to decrease slightly (Table 2), and hence the state dipole moments decrease only somewhat, too. 
It is to be particularly noticed that we must take into consideration the equilibrium molecular geometry upon comparing the state dipole moment in the ground and excited states. In the Table 2 , the state dipole moments calculated upon the geometry optimized in the ground state $\left(\mu_{0}(0)\right.$ and $\left.\mu^{*}(0)\right)$ as well as in the excited "fluorescent" (planar) relaxed state $\left(\mu_{0}(*)\right.$ and $\left.\mu^{*}(*)\right)$ are collected. One can see that relaxation leads to the essential change of the state dipole moment and hence to the change of the values $\Delta \mu$, which corresponds to the sensitivity of the spectra of the merocyanines to the solvent polarity.

Table 2: Dipole moments in the ground state $(\mu 0)$ and excited state $\left(\mu^{*}\right)$ upon the ground state equilibrium geometry $\left((\mu(0))\right.$ and upon relaxed excited geometry $\left.\left((\mu)^{*}\right)\right)$

\begin{tabular}{|c|c|c|c|c|c|c|}
\hline & $\mu_{0}(0)$ & $\mu_{*}(0)$ & $\Delta \mu(0)$ & $\mu_{0}(*)$ & $\mu_{*}(*)$ & $\Delta \mu\left(^{*}\right)$ \\
\hline 1-Py & 11.04 & 10.73 & -0.31 & 10.80 & 7.25 & -3.55 \\
\hline $\mathbf{1 - Q u}$ & 9.14 & 10.55 & 1.41 & 9.66 & 6.37 & -3.29 \\
\hline $\mathbf{1 - P I}$ & 7.66 & 7.69 & 0.03 & 7.63 & 3.37 & -4.26 \\
\hline 1-BIn & 5.70 & 9.72 & 4.02 & 6.71 & 12.97 & 6.26 \\
\hline 1-BIm & 6.56 & 9.85 & 3.29 & 7.88 & 17.54 & 9.66 \\
\hline 1-In & 7.55 & 9.97 & 2.42 & 7.38 & 12.74 & 5.36 \\
\hline
\end{tabular}

\subsection{Absorption Spectra}

The measured absorption spectra of the merocyanines 1 in polar acetonitrile and non-polar toluene are presented in the Figure 3 and Table 3.

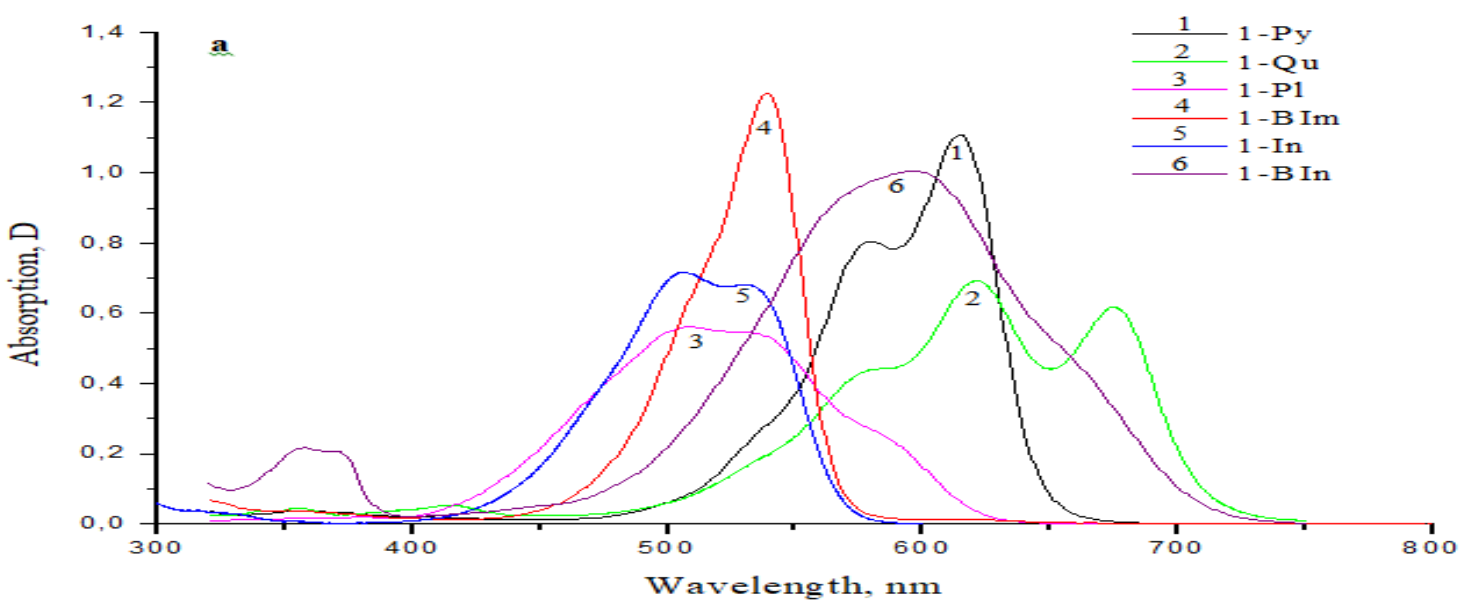






Figure 3: Absorption spectra of the merocyanines 1 in acetonitrile (a) and toluene (b).

The analysis of the spectra of the dyes 1 and comparing them with the absorbance of the corresponding unsubstitued merocyanines have shown that the longwavelength band is shifted bathochromically [6]. Besides, in the pyridomerocyanine, non-structural band in the unsubstitued dye 2 transforms in the typical cyanine-like band with the appreciable vibronical maximum at $582 \mathrm{~nm}$. It enables to assume that band maximum at $571 \mathrm{~nm}$ in the spectra of the unsubstituted dye 2-Py does not correspond to the $0 \rightarrow 0$ ' transition, what can explain too large bathochromic shift of the band maximum (43 nm) upon going to dye 1-Py. The decreasing of the basicity of the end group in the quinomerocyanine causes appearance of the complicated vibronic structure of the absorption band, even with three vibronic maxima in the dye $1-\mathrm{Qu}$, whereas the tried vibronic maximum in the unsubstituted analog is observed only as a shortwavelength shoulder [6]. One can see from Figure 3a that wide absorption band with the shoulders at the short- and londwavelength sides is also observed in the spectra of the 1-Pl and dye 1-BIn.

In the contrast, introducing of the t-Bu substituents in the low basic 1-In is accompanied by the hypsochromic shift of the band maximum, as well as simultaneously by the distortion of the cyanine-like shape of the absorption band in the corresponding unsubstituted merocyanine to the wide band with 2 non-well defined vibronic maxima with equal intensities.

Change of solvent polarity (Figure 3b) causes the change of the band shape in the 1-Py, so that cyanine-like absorption band transforms in the toluene solution in the typical polyene-like spectral band with well-defined vibronical structure with the appreciable decreasing of the intensity. On the contrary, non-structural absorption band in the highly basic 1-BIm increases its intensity in the toluene and becomes practically the same as in the symmetrical cyanine dyes, exhibiting the typical vibronic maximum [10]. In the other dyes, 1-Qu, 1-Pl, 1-In, 1-BIn, going from the AcCN to toluene causes mainly some distribution of the intensities of the vibronic maxima or shoulder and simultaneous shift of them to the shortwavelength spectral region. 
Table 3: Absorption spectral characteristics of the merocyanines 1

\begin{tabular}{|c|c|c|c|c|}
\hline & \multicolumn{2}{|c|}{ Acetonitrile } & \multicolumn{2}{|c|}{ Toluene } \\
\hline & $\lambda_{\max }, \mathrm{nm}$ & $\begin{array}{c}\varepsilon \times 10^{4}, \\
1 \cdot \mathrm{mole}^{-1} \cdot \mathrm{cm}^{-1}\end{array}$ & $\lambda_{\max }, \mathrm{nm}$ & $\begin{array}{c}\varepsilon^{\times 10^{4}}, \\
1 \cdot \mathrm{mole}^{-1} \cdot \mathrm{cm}^{-1}\end{array}$ \\
\hline \multirow[t]{3}{*}{ 1-Py } & 582 & 8.02 & 542 & 5.06 \\
\hline & 614 & 11.04 & 578 & 7.18 \\
\hline & & & 627 & 5.11 \\
\hline \multirow[t]{3}{*}{$1-Q u$} & 579 & 4.38 & 568 & 5.02 \\
\hline & 621 & 6.93 & 606 & 5.39 \\
\hline & 676 & 6.18 & 664 & 2.69 \\
\hline \multirow[t]{3}{*}{ 1-PI } & 507 & $\overline{5.60}$ & 490 & 4.45 \\
\hline & 537 & 5.38 & 522 & 3.83 \\
\hline & 589 & 2.36 & 565 & 1.47 \\
\hline \multirow[t]{3}{*}{ 1-BIn } & 572 & 9.49 & 556 & 9.12 \\
\hline & 596 & 10.05 & 587 & 10.45 \\
\hline & 670 & 3.84 & 647 & 4.43 \\
\hline \multirow[t]{2}{*}{ 1-BIm } & 539 & 12.23 & 520 & 7.62 \\
\hline & & & 552 & 13.69 \\
\hline \multirow[t]{2}{*}{ 1-In } & 506 & 7.16 & 492 & 7.80 \\
\hline & 532 & 6.81 & 519 & 6.08 \\
\hline
\end{tabular}

Then, unfortunately, the such complicated shape of the spectral bands without well-defined $0 \rightarrow$ 0 transition, does not enable to use the absorption spectra for the unambiguous determination of the influence of the effective length of the donor end group on the energy of the lowest electron transition. We have expected that the fluorescence spectra would be more perspective, especially, the spectra measured upon low temperature.

\subsection{Fluorescence Spectra}

The fluorescence spectra can give additional useful information about the electron structure and equilibrium molecular geometry in the relaxed excited state. As a rule, the fluorescence spectra of donor-acceptor conjugated compounds are non-structural, even upon low temperature [9, 10]. 
In the Figure 4, the absorption and fluorescence bands of the 1-In and 2-In in acetonitrile are presented.

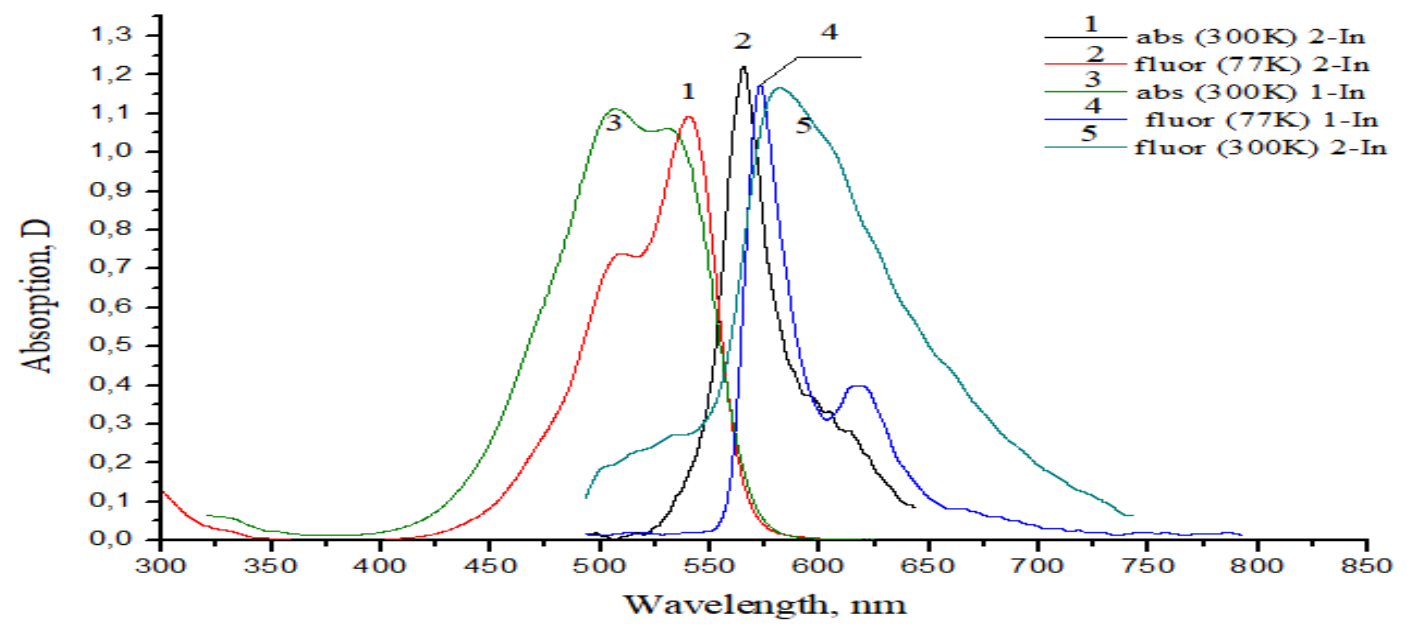

Figure 4: Absorption and fluorescence spectra of merocyanines 1-In and 2-In in acetonitrile. 1absorption spectra of the 2-In, 2-fluorescence spectra of the 2-In at 77K, 3- absorption spectra of the 1-In, 4- fluorescence spectra of the 1-In at 77K, 5- fluorescence spectra of the 2 -In at $300 \mathrm{~K}$.

One can see that the unsubstituted dye 2-In exhibits comparatively wide fluorescence band without the vibronic maximum which is observed in the absorption spectrum. The lowering of the temperature is accompanied by the considerable narrowing of the spectral band, but there observed the appreciable low intensive shoulder at the longwavelength side of the band. We have supposed that this shoulder could correspond to the vibronic $0^{\prime} \rightarrow 1$ transition, and hence have hope that it should appear more distinctly in its t-Bu derivative, 1-In. Really, the well-defined vibronic maximum at $615 \mathrm{~nm}$ is seen from Figure 4 it is observed in the low-temperature fluorescence spectra, so that the distance to the main band maximum is $1053 \mathrm{~cm}^{-1}$, what is typical magnitude for the cyanine dyes [9].

It was found from the calculation (Tab 1) that the bond lengths in the chain of 2-In in the relaxed excited state are more equalized, in comparison with the analog 1-In with $\mathrm{t}-\mathrm{Bu}$ substituents. However, the Stock's shift, $\Delta v_{S}=v_{\max }{ }^{\text {abs }}-v_{\max }^{\text {fl }}$, (more correctly, the conventional Stock's shift, so as here the value $v_{\max }$ is taken from the low-temperature spectra, whereas $v_{\max }{ }^{\text {abs }}$ is measured at $300^{\circ} \mathrm{K}$ ) increases practically by half upon going from dye 2-In $(26 \mathrm{~nm})$ to the 1-In (43 nm) (see Table 4), in the contrast to the well-known Mc-Coy's rule [14] about the proportional relationship between the Stock's shift, $\Delta v_{\mathrm{S}}$, and the total change of the bond lengths upon relaxation in the excited state, $\delta(2)$ :

$$
\delta=\sqrt{ } \sum\left(1_{\mu \nu}{ }^{*}-1_{\mu \nu}{ }^{0}\right)
$$

Where summation runs over all bonds.

The low-temperature fluorescence spectra of all the merocyanines 1 in two solvents are presented in the Figure 5. 


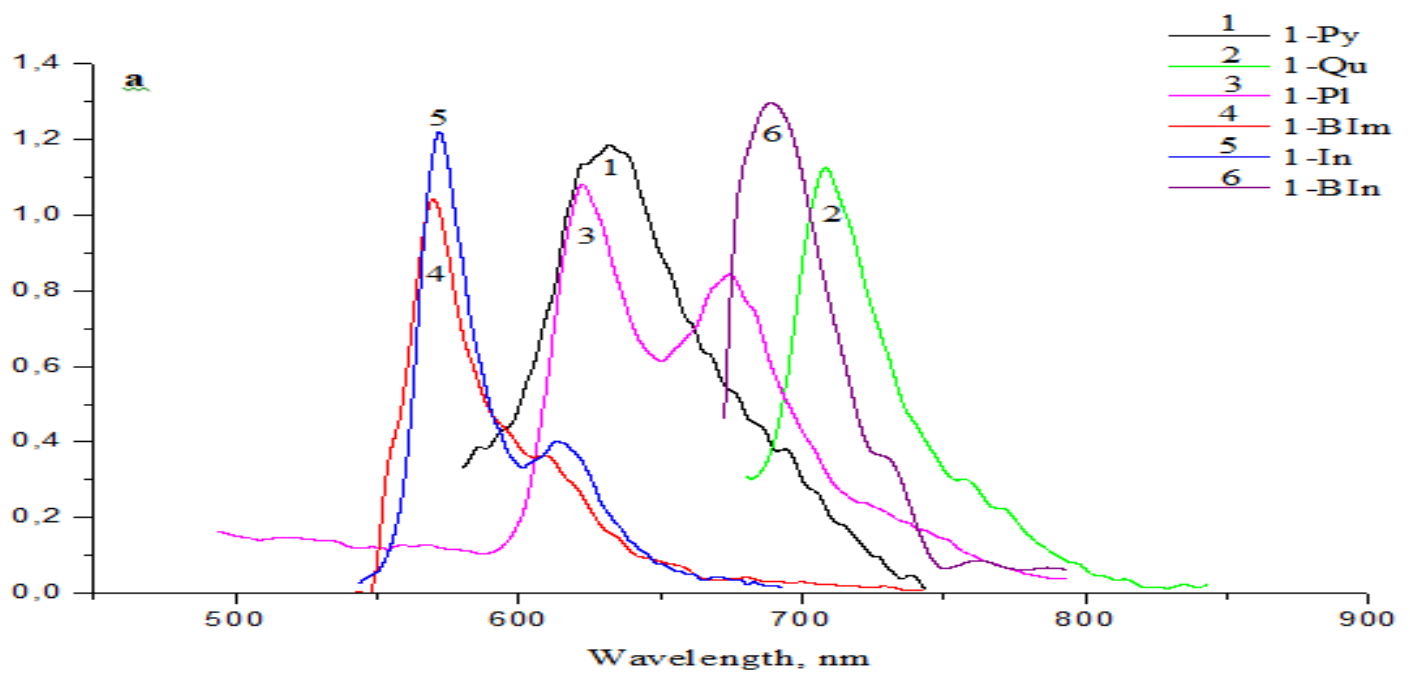

Figure 5: Fluorescence spectra at 77K of the merocyanines 1 in acetonitrile (a) and toluene (b).

Comparing them with the absorption spectra (Figure 3) as well as with both high and low temperature fluorescence spectra of the 2-In (Figure 4) shows that there are not principal distinguishing features between them, and hence the fluorescence spectra in the Figure 5 should correspond to the usual longwavelength fluorescence.

One can see that only 1-Pl demonstrates well-defined vibronic structure of the spectral band. The distance between both vibronic maxima remains practically the same in the acetonitrile (1262 $\left.\mathrm{cm}^{-1}\right)$ and non-polar toluene $\left(1256 \mathrm{~cm}^{-1}\right)$. Based on the position of the fluorescent band maxima, we can state that $0 \rightarrow 0$ vibronic transition in the absorption spectra (Figure 3) does not correspond to the band maximum at $507 \mathrm{~nm}(\mathrm{AcCN})$ or $490 \mathrm{~nm}$ (toluene), as the highest intensive maximum, but to the longwavelength shoulder, approximately, at $589 \mathrm{~nm}$ in acetonitrile or at $565 \mathrm{~nm}$ in the toluene (see Table 3). Then the observed Stock's shift $\left(927 \mathrm{~cm}^{-1}\right.$ and $1544 \mathrm{~cm}^{-1}$, correspondingly) is of the same order as in the other dyes (see Table 4).

Table 4: Fluorescence spectral characteristics of the merocyanines 1

\begin{tabular}{|c|c|c|c|c|c|c|c|}
\hline & \multicolumn{4}{|c|}{ Acetonitrile } & \multicolumn{3}{|c|}{ Toluene } \\
\hline & \multirow[t]{2}{*}{$\lambda_{\max }, n m$} & \multirow[t]{2}{*}{$\Delta \lambda, n m$} & \multicolumn{2}{|c|}{ Stock's shift } & \multirow[t]{2}{*}{$\lambda_{\max }, \mathrm{nm}$} & \multicolumn{2}{|c|}{ Stock's shift } \\
\hline & & & $\Delta \lambda_{S}, n m$ & $\Delta v_{S}, \mathrm{~cm}^{-1}$ & & $\Delta \lambda_{S}, n m$ & $\Delta v_{S}, \mathrm{~cm}^{-}$ \\
\hline 1-Py & 631 & 58 & 17 & 439 & 629 & 2 & 51 \\
\hline $1-Q u$ & 708 & 135 & 32 & 669 & 704 & 40 & 856 \\
\hline 1-PI & 623 & 50 & 34 & 927 & 619 & 54 & 1544 \\
\hline 1-BIn & 689 & 116 & 19 & 412 & 663 & 16 & 373 \\
\hline
\end{tabular}




\begin{tabular}{|c|c|c|c|c|c|c|c|}
\hline 1-BIm & 570 & -3 & 31 & 1009 & 552 & 0 & 0 \\
\hline 1-In & 573 & --- & 41 & 1345 & 563 & 44 & 1506 \\
\hline
\end{tabular}

Similar structural fluorescent bands with the additional vibronic transition are also observed for the shortwavelength dyes 1-BIn and 1-In, but only in the acetonitrile (Figure 5a). The rest merocyanines do not demonstrate the similar defined vibronic structure. It is to be noted that the distinct structure with 2 or even 3 vibronic maxima in the absorption spectra of the 1-Py in the toluene and of the 1-Qu in both solvents disappear in the fluorescence spectra. Such considerable change of the shape of the spectral bands upon going from absorption spectra to the fluorescence leads their maxima for the dye 1-Py and 1-BIm in toluene even to coincide, whereas the Stock's shifts in the AcCN are appreciable, particularly, in the spectra of 1-BIm $\left(1040 \mathrm{~cm}^{-1}\right)$. For the other dyes, the value $\Delta v_{S}$ increases somewhat upon going from the polar solvent to the non-polar one (compare corresponding data in the Table 4). Also, the essential transformation of the band shape in the absorption and fluorescence bands can likely explain an absence of the correlation between the Stock's shift, $\Delta v_{\mathrm{S}}$, and the calculated magnitudes of the parameter $\delta$ (Table 1). So, the calculations have given the minimum value $\delta$ for the dyes 1-BIm (0.892) and 1-In (1.013), whereas the corresponding spectra have given the maximum the Stock's shifts in the acetonitrile: $1009 \mathrm{~cm}^{-1}$ and $1345 \mathrm{~cm}^{-1}$.

Now, based on the well-defined $0 \rightarrow 0$ transitions in the low-temperature spectra of the fluorescence, we can estimate the spectral influence of the effective length of the donor residue Het=. We will compare the spectral data of any merocyanine 1 or symmetrical cyanine 4 with the corresponding dye containing indolenine residue (In). So, the symmetrical 4-In absorbs at the shortest wavelengths. It is seen from Table 4 that going to the 1-BIm is accompanied by the comparatively small hypsochromic shift: $\Delta \lambda=-3 \mathrm{~nm}$, what is near to the corresponding spectral effect in the symmetrical dyes 4-In and 4-BIm: $\Delta \lambda=-7 \mathrm{~nm}$ [15]. It is to be noted that the absorption band maxima are also close: $532 \mathrm{~nm}$ and $539 \mathrm{~nm}$ for the pair 1-In and 1-BIm; $545 \mathrm{~nm}$ and $553 \mathrm{~nm}$ for the symmetrical dyes 4-In and 4-BIm [14]. The opposite sign of the spectral effect in the absorption spectrum in comparison with the fluorescence is connected with the larger Stock's shift in the dyes containing low basic indolenine residue, so that: $\Delta v_{\mathrm{S}}=743 \mathrm{~cm}^{-1}$ (4-In) and $\Delta v_{S}=590 \mathrm{~cm}^{-1}$ (4-BIm), while for the merocyanines: $\Delta v_{\mathrm{S}}=1345 \mathrm{~cm}^{-1}(1-\mathrm{BIm})$ and $\Delta v_{\mathrm{S}}=1009 \mathrm{~cm}^{-1}(1-\mathrm{In})$.

In the contrast, the symmetrical cyanines 4-Qu and 4-BIn, the fluorescence band maximum is proved to be shifted bathochromically on the $147 \mathrm{~nm}$ and $212 \mathrm{~nm}$, in respect to the indocarbocyanine 4-In. One can see from Table 4 and Figure 5 that the similar large bathochromic effects are also observed for the corresponding merocyanines 1-Qu and 1-BIn, although they are somewhat smaller: $135 \mathrm{~nm}$ and $116 \mathrm{~nm}$. Such decreasing of the spectral effects could be connected with the considerable change of the state dipole moments upon the electron transition, $\Delta \mu$ (see Table 2), and hence with the influence of the solvent polarity, which can remain at the low temperature because of the impossibility of the rearrangement of the solvent shell. 
The replacing of the indolenine residue by pyridine $(\mathrm{Py})$ or pyrilium $(\mathrm{Pl})$ end groups in the merocyanines 1 causes also comparatively large bathochromic shift of the fluorescence band maximum: $58 \mathrm{~nm}$ and $50 \mathrm{~nm}$, correspondingly. The obtained magnitudes are near to the spectral effects of these terminal groups in the absorption spectra of the symmetrical dyes: $58 \mathrm{~nm}$ (4-Py) and $62 \mathrm{~nm}(4-\mathrm{Pl})$.

\section{Conclusion}

Thus, the more stable neutral merocyanines $\mathbf{1}$ absorb and emit the light at the relatively longwavelengths, similarly to the corresponding symmetrical cyanines, in the contrast to the unsymmetrical cationic oxystyryls and to another type of the neutral donor-acceptor derivatives of the cyanines - their bases. Well-defined $0 \rightarrow 0$ vibronical transition was found of merocyanines, derivatives of the 2,6-di-tret-butyl substituted cyclohexa-2,5-dienone at use of the low-temperature fluorescent spectra. The analysis of the spectra has shown that the spectral effect do the donor groups in the merocyanones is similar to the symmetrical cyanines. Therefore, more stable merocyanines $\mathbf{1}$ can be used as fluorescence probes and labels in chemistry and biology, active and passive components for tunable dye lasers, highly effective materials for non-linear optic.

\section{References}

[1] Reichardt Ch. Solvent effects in organic chemistry. Weinhein: Verlag Chemie; 1979, p.320.

[2] Botrel A., Beuze A., Jaques P., Strub H. (1984) Solvatochromism of a typical merocyanine dye. A theoretical investigation through the CNDO/SCI method including solvation J. Chem. Soc., Faraday Trans. 2 (80) 1235-1252. DOI: 10.1039/F29848001235

[3] Baraldi I., Momicchioli F., Ponterini G., Vanossi D. (1998) Exciton-like and charge-transfer states in cyanine-oxonol ion pairs. An experimental and theoretical study Chem. Phys., 238, 353364. DOI: $10.1021 / j p 004479 t$

[4] F.Meyers, S.R.Marder, J.W.Perry (1998) Introducing to the Nonlinear Optical Properties of Organic Materials. In: Chemistry of Advanced Materials. An Overreviw. Chapt. 6. Ed. L.V.Interrante, M.J.Hampden-Smith. Wiley-VCH. Inc. New-York-Chicherster-WeinheimBrisbane-Singapore-Toronto. P.207-268.

[5] Risser S.M., Beratan D.N., Marder S.R. (1993) Structure-function relationships for .beta., the first molecular hyperpolarizability J. Amer. Chem. Soc., 115, 7719-7728. DOI: 10.1021/ja00070a016

[6] Pilipchuk N. V., Kachkovsky G. O., Slominskii Yu. L., Kachkovsky O. D. (2006) Electronic properties of polymethine systems. 11. Absorption spectra and nature of electron transitions in cationic oxystyryl and their neutral derivatives. Dyes \& Pigments, 71, 1-9. DOI: 10.1016/j.dyepig.2005.04.013

[7] Brooker L.Y.S., Keyes G., Sprague L. H. (1951) Color and Constitution. X. Absorption of the Merocyanines. J. Amer. Chem. Soc., 73, 5332-5350. DOI: 10.1021/ja01155a096

[8] Hamer F.M. Cyanine dyes and related compounds. Interscience. New York. 1964

[9] Tyutulkov N., Fabian J., Mehlhorn A., Dietz F., Tatjer A. (1991) Polymethine Dyes. Structure and properties. St. Kliment Ohridski University Press,Sofia.

[10] Kachkovsky O. D., Pilipchuk N. V., Piryatinski Yu. P., Kachkovsky G. O., Slominskii Yu. L. (2007). Low-temperature fluorescence of oxystyryls and some of their neutral derivatives. Dyes \& Pigments 73, 353-360. DOI: 10.1016/j.dyepig.2006.01.046

[11] Kachkovsky A.D. (1997) The nature of electronic transitions in linear conjugated systems. Russ. Chem.Rev. 66, 647-664. DOI: 10.1070/RC1997v066n08ABEH000274 
[12] Gruda I., Bolduc F. (1984) Spectral properties and basicity of stilbazolium betaines containing bulky substituents on the quinoid ring. J. Org. Chem. 49, 3300-3305. DOI: 10.1021/jo00192a010

[13] Streitwieser A. (1963) Molecular orbital theory. New York-London: John Wiley and Sons, Inc.

[14] McCoy E.F., Ross I.J. (1962) Electronic States of Aromatic Hydrocarbons: The Franck-Condon Principle and Geometries in Excited States Austral. J. Chem., 15, 573-590. DOI: $10.1071 / \mathrm{CH} 9620573$

[15] Ishchenko, A.A. (1991) Structure and Luminescence-Spectral Characteristics of Polymethine Dyes. Russ. Chem. Rev., 60, 865-880.

[16] M. J. Frisch, G. W. Trucks, H. B. Schlegel, at al, (2003) GAUSSIAN03; revision B.05, Gaussian, Inc., Pittsburgh PA.

*Corresponding author.

E-mail address: nataliya.obernikhina @nmu.ua 